in the electron microscope. Spiral growth was evident in numerous specimens obtained from both hot xylene and benzene solutions. Fig. 1 illustrates one of the simplest examples of this growth, showing growth from a single spiral. Generally, more complicated effects are observed due to the impingement of growth layers. In larger aggregates, the lozenge shape seems to persist.

I wish to thank the Phillips Petroleum Co. for their specimen.

Physics Department, Stevens Institute of Technology,

Hoboken, New Jersey.

$$
\text { March } 15 .
$$

1 Mott, N. F., Nature, 165, 295 (1950).

"Griffin, L. J., Phil. Mag., 41, 196 (1950).

- Frank, F. C., Farad. Soc. Discuss. on Crystal Growth, No. 5 (1948).

4 Dawson and Vand, Nature, 167, 476 (1951).

"Forty, A. J., "Advances in Physics", 3, No. 9 (1954).

-Verma, "Crystal Growth and Dislocations" (Academic Press, Inc.)

" Williams, R. C., and Wyckoff, R. W. G., J. App. Phys., 17, 23 (1946).

\section{Reduction in X-ray Sensitivity of Seeds by Hydration}

Numerous investigators have reported that when seeds are soaked there is a parallel increase in their water content and sensitivity to X-rays ${ }^{1}$. These studies have been taken as strong support for the postulate that much radiation injury results 'indirectly' from the decomposition and/or ionization of water. Therefore, it was of some concern to us when it was shown there was actually an inverse relationship between the water content of dormant barley seeds and their sensitivity to X-rays ${ }^{2}$. For this reason it seemed desirable to re-investigate the relation between radiosensitivity and the water content of soaked seeds.

Dormant seeds, originally stored over phosphorus pentoxide until they reached weight equilibrium, were soaked at $0^{\circ} \mathrm{C}$. and $22^{\circ} \mathrm{C}$. for different periods of time and then subjected to X-rays. They were grown for seven days and the average heights of the seedlings compared with those of irradiated unsoaked seeds (Fig. 1).

From these results it is clear that the sensitivity of seeds to X-rays decreases after one hour of soaking at $22^{\circ} \mathrm{C}$. However, after four hours soaking they are about as sensitive as dry controls. In contrast to this, when soaked at $0^{\circ} \mathrm{C}$. the seeds slowly increase

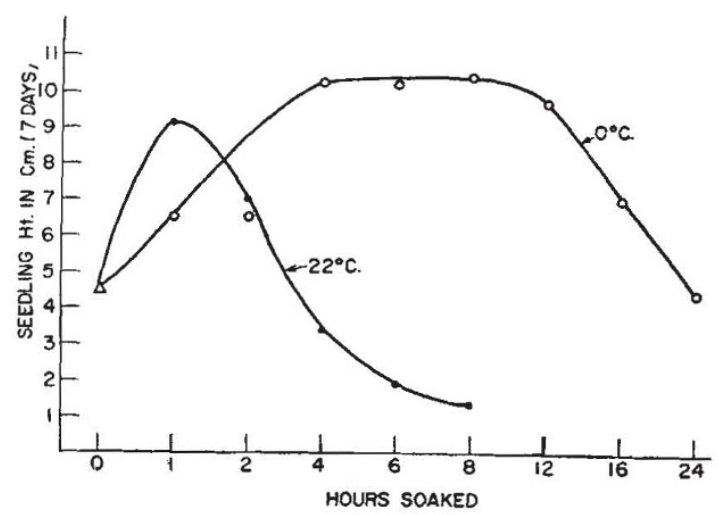

Fig. 1. Effects of soaking barley seeds at $22^{\circ} \mathrm{C}$. and $0^{\circ} \mathrm{C}$. on their sensitivity to $15,000 \mathrm{r}$. of X-rays in resistance to X-rays, so that after four hours they reach a point of maximum resistance comparable to that obtained after one hour soaking at $22^{\circ} \mathrm{C}$. They maintain this level of tolerance when the soaking period is extended up to eight hours. However, further soaking results in a gradual increase in sensitivity and after $24 \mathrm{hr}$. they are about as sensitive to $\mathrm{X}$-rays as the dry control. It is significant that the embryo rapidly absorbs water, and the water content of embryos of seeds soaked at both tem. peratures for one hour equals about 40 per cent of their wet weight. After $24 \mathrm{hr}$. soaking it only increased to about 60 per cent. The corresponding water content of the embryo of the dry control was 4 per cent.

Two points seem clear from this work: (1) the X-ray sensitivity of dry seeds can actually be decreased by periods of soaking at both $0^{\circ} \mathrm{C}$. and $22^{\circ} \mathrm{C}$.; (2) the duration of the reduced sensitivity is related to the temperature of the steeping water and is probably associated with increased physiological activity.

These results suggest that the radio-decomposition of water may play a less significant part in modifying radiosensitivity than has previously been assigned to it.

Part of this work was carried out at Brookhaven National Laboratory under the auspices of the U.S. Atomic Energy Commission.

U.S. Department of Agriculture, RichaRd S. CALDFCOTT University of Minnesota, and the

Brookhaven National Laboratory.

1 Gustafsson, A.. Hereditas, 33, 1 (1947).

2 Caldecott, R. S., Science, 120, 809 (1954). Ehrenberg, L., and Nybom, N., Acta Agric. Scand., 4, 396 (1954).

\section{Distribution of Radiocarbon in Tobacco Mosaic Virus}

WE have made radioactive tobacco mosaic virus by exposing leaves from infected tobacco plants to radioactive carbon dioxide for one day in light, treating the homogenized leaves with buffer solution, and purifying the virus by repeated precipitation at the isoelectric point ${ }^{1}$. The virus is determined by colour reaction, burmed, and the radioactivity of the resulting carbon dioxide measured with a gas Geiger counter ${ }^{2}$. It has been found that the specific radioactivity (activity per unit weight) of the virus decreases with increasing 'age', that is, with increasing timeinterval between infection and radiophotosynthesis, up to an age of about four weeks ${ }^{3,4}$. In addition, one sample of tobacco mosaic virus, aged two months, was analysed for distribution of radioactivity. The nucleic acid was split off by treatment with trichloroacetic acid ${ }^{5}$, and the protein hydrolysed and divided into the individual amino-acids by column chromatography'. A large part of the radiocarbon was found in the nucleic acid, and the distribution of the radiocarbon among the individual amino-acids was quite uneven ${ }^{7}$.

Using the methods described, we have now determined the distribution of the radiocarbon between nucleic acid and protein as a function of age of the virus. The samples of tobacco mosaic virus were the same as those used in the previous work 4 . The seeds had been sown in March, the plants transferred to the open field in May, and infected (first series; $A$ ) early in July, or (second series; $B$ ) late 